\title{
Experimentações Coletivas por Entre Poesias, Fotografias e Ventos-Áfricas
}

\section{Collective Trialsthrough Poetry, Photographs and Wind-Áfricas}

Resumo: Esse artigo discute as potencialidades políticas e poéticas da fotografia e da escrita para a educação, a partir das oficinas de experimentações coletivas do Projeto Fabulografias em Áfricas-Cartões-Postais. Busca por uma política visual, que conceba a imagem não como representação intacta de uma certa visibilidade, mas como possibilidades de criação de novas visualidades, na aproximação com a arte. Aposta na composição entre a criação do pensamento e da arte, como forma de potencializar conversas na área da educação e estudos da escrita e imagem, tendo os pensamentos de Gilles Deleuze como principais movimentadores teóricos. Assume as linguagens visuais e verbais como experimentação coletiva na educação, propondo a mixagem entre palavras, imagens e culturas.

Palavras-chave: Fotografia. Poesia. Gilles Deleuze. Experimentação. Criação coletiva.

\begin{abstract}
This article discuss the political and poetic potential of photography and writing to education, through collective trial workshops from the Project Fabulografias in áfricas-postcards. Searching for a visual politic, which sees the image not as a frozen representation of a certain visibility, but as opportunities to create new visualities, as a closeness with the art. A bet in the composition between the creation of thought and art, as a way to boost talks on education and culture, considering Gilles Deleuze thoughts as main theoretical movers. Assume the verbal and visual languages as collective experimentation in education, suggesting a mix between words, images and cultures.

Key-words: Photography. Poetry. Gilles Deleuze. Experimentation. Collective creation.
\end{abstract}

WUNDER, Alik; ROMAGUERA, Alda Regina Tognini. Experimentações Coletivas por Entre Poesias, Fotografias e Ventos-Áfricas. Informática na Educação: teoria e prática, Porto Alegre, v. 17, n. 2, p. 31-45, jul./dez. 2014.
Alik Wunder

Universidade Estadual de Campinas

\section{Alda Regina Tognini Romaguera \\ Universidade de Sorocaba}

\section{Imagem e Educação: que áfricas ventam por você?}

E sse artigo discute as potencialidades políticas e poéticas da fotografia e da escrita para a educação, a partir das oficinas de experimentações coletivas do Projeto Fabulografias em Áfricas-Cartões-Postais ${ }^{1}$. Por este projeto perpassam criações com palavras, imagens e sons, que acontecem nos encontros entre pesquisadores, artistas - fotógrafos, designer gráficos, músicos, vídeo-maker -,

1 O projeto de extensão Fabulografias em Áfricas-Cartões-Postais, sob a responsabilidade do prof. Dr. Antonio Carlos Rodrigues de Amorim, foi coordenado por Alik Wunder e realizado entre 2010 e 2011 (FAEPEX-Unicamp) com o grupo de estudos Humor Aquoso, ligado ao Laboratório de Estudos Audiovisuais - OLHO - Faculdade de Educação, Unicamp e grupo de pesquisa MultiTÃO: prolifer-artessub-vertendo ciências e educações (Labjor - Unicamp). Mais informações no site: www.fabulografias.com. 
alunos de ensino médio de escolas públicas e grupos que lidam com a cultura afro-brasileira por meio da música, dança, culinária, teatro na cidade de Campinas ${ }^{2}$.

Pensado incialmente como projeto de extensão universitária, o Fabulografias gerou, entre os anos de 2010 e 2012, diversos encontros de criação e foi motivado pelo desejo de partilhar com artistas, alunos e grupos culturais, os pensamentos gerados em nossos grupos de pesquisas. Associada ao projeto de pesquisa $A$ Quem Será que se Destina? Imagens e palavras pós-estruturam a escola... (Edital CNPQ de Ciências Humanas e Sociais) ${ }^{3}$, esta proposta integra uma linha de pesquisa, que tem sido criada pelo grupo de estudos Humor Aquoso (Faculdade de Educação - Unicamp) em investigações que relacionam educação, imagens e filosofia potencializando a discussão, com Gilles Deleuze, sobre conceitos de sentido e representação, fundamentais para o estudo dessas temáticas contemporâneas. Busca-se por uma política visual que conceba as imagens não como representação intacta

\footnotetext{
${ }^{2}$ Este agrupamento de pessoas foi denominado por nós Coletivo Fabulografias, que assina a autoria das criações fotográficas e poéticas deste artigo. O Coletivo Fabulografias nestes dois anos de trabalho foi constituído por: equipe de pesquisadores e bolsistas de ensino médio (PIBIC Jr) e graduação (PIBIC e SAE): Alik Wunder, Alda Romaguera, Antonio Carlos Amorim, Davina Marques, Gustavo Torrezan, Vinícius Bastos, Marcelo Pupo, Marcus Novaes, Celisa Susana Dias, Érica Speglich, Ivânia Marques, Geyse Porto, Lais Nunes, Larissa Gaulia; LaisJaciane, Laura Fernin, Alessandra Melo, Kildery Monteiro, Bruna Gama, Rafael dos Santos e Cláudio Camargo. Grupos e artistas convidados: Bia Porto (artista visual), Marli Wunder (fotógrafa), Nil Sena (arte-educadora, grupos Urucungos, Pítas e Quinjenges) Associação dos Benfeitores dos Bailarinos e Atores (ABAMBA); Leonice Sampaio Antonio - Tia Nice (cozinheira), Sebastião Vitor Rosa - Companhia de Santo Reis Azes do Brasil (mestre de folia de reis), Grupo de Samba Saracura, Fábio Queiroz, Comunidade Jongo Dito Ribeiro - Projeto duas Marias e uma Edith, Matriarcas do Samba de Bumbo de Campinas; Grupo Cultural Netos de Bandim (Guiné-Bissau), Marilde Stropp (fotografia) e Odair Mechi Soares (montagem de cenários e exposições). Alunos de escolas públicas: E. E. Vicente Cury: Willian Dias, Thiago Santos, Cintia Cavaglieri, Cláudia da Silva, Milena Lima, Larissa de Oliveira, Bianca Macedo, Tainá Lucio, Melissa Cristina e Felipe Manzano.

${ }^{3}$ Coordenado por Antonio Carlos Rodrigues de Amorim, professor da Faculdade de Educação - Unicamp.
}

de uma certa visibilidade, mas como possibilidades de criação de novas visualidades, na aproximação com a arte. As pesquisas investem em experimentações de escrita com-por-entre imagens (pintura, fotografia, cinema, vídeos experimentais...), tendo a linguagem como efeitos de superfície. A profundidade e o preenchimento sempre insuficientes são o que, para Deleuze, torna possível a linguagem, como nascimento, como novidade, como devir-ilimitado (AMORIM, 2012). Este artigo vê a composição entre a criação do pensamento e da arte, como forma de potencializar conversas entre as áreas da educação, estudos da escrita, da imagem e da cultura.

\section{Movimentando Respostas aos Ventos-Áfricas: fabulações fotográ- ficas}

ousar

misturar no instante imagens, cores e sons

a dançar com-por um foto-poema entrelaçado

lançado a

postal

que áfricas ventam por você?

Em 2010, iniciamos os encontros de criação fotográfica coletiva, com grupos que lidam diretamente com a cultura afro-brasileira, tais como grupos de dança, capoeira, samba, congado, jongo... Lançamos uma pergunta, que desafiava nossas criações: que áfricas ventam por vocês? Os encontros, que ocorreram em casas de cultura da cidade, assemelhavam-se a saraus; neles, as respostas chegaram por objetos, adereços, cantos, imagens, danças, histórias, performances, encenações... No início os encontros eram fotografados pelos pes- 
quisadores e fotógrafos convidados que, por sua vez, convidavam as pessoas a se fotografarem e fotografarem os outros. Projeções de imagens e palavras sobre os corpos interagiam com as respostas partilhadas, cenários se faziam em inesperados encontros entre corpos, imagens, luzes, sons. A câmera rodava de mão em mão. Além de experimentações fotográficas, inserimos experimentações de pós-produção por meio de programas de manipulação de imagem, bem como manipulações artesanais: colagem, escrita e desenho sobre imagem. A cada encontro imagens eram selecionadas, algumas pós-produzidas em programas de computador por artistas convidados e, nos encontros seguintes, compartilhadas com os participantes na forma de cartões-postais.

Os encontros expandiram-se para escolas públicas de Campinas, nos quais alunos eram convidados a processos coletivos de criação estimulados pela mesma pergunta. $\mathrm{E}$ as respostas também chegavam por objetos, por encenações desdobradas em fotografias e posteriormente em criações poéticas. Um fluxo de imagens e palavras foi sendo criado entre pessoas: respostas ao vento. As oficinas-saraus, tanto nas escolas como nos centros culturais, iniciavam-se sempre com a apresentação dos postais criados nos encontros anteriores: um banquete de imagens servido em grande mesa. Apostou-se na potência das imagens gerarem encontros entre grupos de cultura afro-brasileira, entre alunos e professores de escolas públicas, entre universitários, entre artistas convidados... Um fluxo que se expandiu na $w e b^{4}$ e em exposições realizadas nos anos de 2012 e 2013 em diversos espaços da cidade de Campinas (SP) e região.

\footnotetext{
4 Disponível em: <www.fabulografias.com>; <fabulografias-alb.wordpress.com>; <www.facebook.com/fabulografias. africascartoespostais $>$.
}

Desafiados a fotografar os ventos, os traços das culturas afro-brasileiras que nos perpassam, fomos lançados a fotografar o invisível, o incapturável, o inapreensível; traços de cultura em movimento, que recorrentemente desejam ser capturados e territorializados pelos discursos imagéticos e verbais que seguem a lógica da representação. Os cartões-postais podem ser pensados como ícones do clichê fotográfico. A cultura visual que se produz nas mídias, nas publicidades, nas escolas, nas ciências, nas redes de internet geram cartões-postais: as imagens em repetição que, além de afirmarem as culturas por aquilo que se escolhe como característico e essencial, também se pautam na verossimilhança, na relação direta entre imagem e mundo. Estas imagens, que se afirmam reais, criam verdades identitárias que estabilizam as compreensões das dinâmicas culturais. Imagens e palavras que, pela repetição, dão às culturas formas rígidas como desejo de fixá-las e nomeá-las. Clichês se proliferam para muitas direções pela afirmação de verdades únicas e pelas lógicas da sobreposição, da estabilização, da falta de forças de desequilíbrio e da incerteza amansada.

Nos diversos encontros, as criações fotográficas dialogavam com clichês sobre as culturas africanas e afro-brasileiras recorrentes em livros didáticos brasileiros, por vezes gerando tensões e por vezes reafirmando-os: o afro-brasileiro marcado pelo seu passado de escravidão e o africano como habitante de um continente assolado pela pobreza. O tensionamento destes clichês provinha especialmente dos grupos artísticos e de alunos de escolas públicas ligados a grupos culturais e de religião afro-brasileira que afirmavam, nas criações fotográficas, a força, a beleza, a resistência da cultura afro-brasileira nos corpos - pele, cabelo, rosto - na música - tambores, chocalhos, 
voz - na dança - gestos e movimentos - nos objetos - estatuetas, búzios, sementes, turbantes, saias, colares... Afirmavam uma África fabulada por diversas manifestações culturais, que pulsam de forma plural, fortemente silenciada na escola e nos livros didáticos. Havia o desejo de criar outras imagens para afirmar outras verdades, como contraposição ao silenciamento que reafirma o desconhecimento e o preconceito, intensamente presente, especialmente nos espaços escolares. E neste desejo de expressão de verdades, havia sempre o risco da proliferação de outros clichês: a africanidade exclusivamente negra e a África apenas como um lugar de belezas. Nos encontros, apostou-se em processos de criação nos quais os clichês não eram descartados, mas continuamente rasurados, desdobrados, recontextualizados, triturados, esvaziados, novamente preenchidos. Apostou-se assim numa possibilidade de atravessar os clichês deixando um rastro de ficcionalidade, uma potência da arte no pensamento e na educação que não se quer verdade única, mas que se abre à multiplicidade de verdades singulares.

Com estas experiências, pretendemos aqui pensar as culturas imbricadas nas linguagens visual e verbal. Linguagens que, na pulsão da arte, aceitam-se incompletas, que não traduzem representações anteriores (ou interiores), mas que produzem sentidos contingentes e fugazes, em movimento constante. Compartilhando pensamentos de Veiga-Neto (2003) sobre o pensamento pós-estruturalista e suas implicações para a área da educação e cultura, entendemos que "[...] estamos sempre e irremediavelmente mergulhados na linguagem e numa cultura, de modo que aquilo que dizemos sobre elas não está jamais isento delas mesmas [...]" (VEIGA-NETO, 2003, p. 14). Uma cultura que se faz por imagens e palavras.
Imagens e palavras que se criam na cultura. $E$ nesta dinâmica, não há como fugir dos clichês. Deleuze (2007, p. 33) diz que devemos "[...] rivalizar o clichê dentro de seu próprio terreno $[\ldots] "$. Sobre a tentativa dos diretores de cinema em buscar novas imagens, diz:

Às vezes é preciso restaurar as partes perdidas, encontrar tudo o que não se vê na imagem, tudo o que foi subtraído para torná-la 'interessante'. Mas às vezes ao contrário, é preciso fazer buracos, introduzir vazios e espaços em branco, rarefazer a imagem, suprimir dela muitas coisas que foram acrescentadas para nos fazer crer que víamos tudo (DELEUZE, 2007, p. 32).

Para ir a busca dos espaços vazios, das subtrações, do rareamento das imagens, do desinteressante, lidamos inevitavelmente com os clichês, que estão em nossas memórias visuais, eles são a base por onde deslizam os processos de criação. É a partir destes clichês, e no desejo contínuo de atravessá-los, que as criações fotográficas se fazem. Pesquisamos formas de criar postais que não sejam óbvios, fixos, esperados, que aceitem a impossibilidade de fixar o incapturável: os ventos-áfricas que nos atravessam.

Lidar com a criação fotográfica e a escrita pela pulsão experimental pareceu um caminho potente. No campo da fotografia, buscamos inspirações em diversos fotógrafos brasileiros e estrangeiros. Acompanharam-nos nestas experimentações: a série Os Anturos de Eustáquio Neves (2005), os Sonhos de Cláudia Andujar (2005), o Entre os Olhos, o Deserto de Miguel Rio Branco (2003), o Metabiótica de Alexandre Órion (2006), o Sem Simpatia de Paula Trope, Le Retour Imaginaire de Jorma Puranen. Fotógrafos que tencionam, deslocam, subvertem o caráter evidencial e representacional das fotografias, no sentido de uma ima- 
gem que aconteça em sua própria superfície, produzindo signos que indicam outras possibilidades de comunicação e educação, outras políticas e poéticas visuais (WUNDER; DIAS, 2010, p. 158). Nas oficinas, lidamos com a fotografia como uma superfície de experimentação no ato de fotografar - em enquadramentos incomuns, na criação de cenários e encenações, ao fotografar movimentos, fotografar projeções sobre corpos, fotografar fotografias em diferentes contextos, compor objetos sobre fotografias - e na pós-produção fotográfica programas de computador, recortes e rasuras manuais e escritas sobre imagem. Na mistura entre os diferentes postais criados, já não se sabe se manipulados ou não, se reais ou não, e já não importa a pergunta.

As manipulações lidam com a potência de fabulação da imagem, são manipulações em giros, em muitas mãos, sem necessidades determinísticas de representar ventos-áfricas individuais. Enunciados coletivos que se criam atravessados por ventos muitos, em um movimento de ficção do mundo, criação de um mundo-imagem. Como nos escritos de Krauss (2002) sobre fotógrafos surrealistas, buscamos a fotografia como arte da mão e não dos olhos. As experimentações fotográficas propostas pretendem tirar a fotografia do campo da visão e lançá-la ao campo da invisibilidade, das sensações que extravasam os olhos. Uma imagem que deixe de pressupor uma realidade e de remeter a uma forma aceita como verdadeira, um pensamento que abandone o questionamento sobre a verdade ou falsidade, uma criação que entre no movimento de indiscernibilidade entre o real e o imaginário (DELEUZE, 2007).

\section{Oficinas de Escrita Experimental}

escrever para que? criar uma língua de/por/com imagens jogar com as palavras, fragmentar fazer ver ou ouvir sensações-ventos caberia o vento em um cartão postal?

(con)versar com imagens nos versos dos postais

avessos reversos

versos a versar

escrever para quem? para um/a leitor/a desconhecido/a... leitor qualquer escrever para experimentar transitar pelo infinito da vida possível

Nas oficinas seguintes o desafio se verteu à escrita nos versos dos postais, numa criação poética coletiva realizada no limite do espaço de um cartão postal, em que poucas palavras potencializam a expressividade. Foram oferecidos aos participantes papéis em formato postal para a realização de um exercício de criação provocado pelas leituras anteriores e pelo contato com as imagens. Deste contato com leituras e imagens derivaram múltiplas propostas de interação. Por exemplo, ao dar continuidade a um fragmento alheio, compor escritos para imagens produzidas pelo coletivo, misturar trechos de poemas entre si ou com palavras criadas nestes encontros texto/imagens; pretendia-se provocar o estilhaçamento da autoria e o esgarçamento da identidade, para que o postal não ficasse prisioneiro de um quem e de um para que. Dizendo com Derrida:

O que prefiro no cartão-postal é que não se sabe o que está na frente ou o que está atrás, aqui ou lá, perto ou longe, o Platão ou o Sócrates, frente ou verso. Nem o que mais 
importa, a imagem ou o texto, e no texto, a mensagem ou a legenda, ou o endereço. (DERRIDA, 2007, p. 19)

Explorar possibilidades de criar uma língua de/por/com imagens, jogando com as palavras, fragmentando-as, foi a nossa aposta por uma escrita também como experimentação, entendida como possibilidade de exercício do pensamento e enquanto propulsora dos acontecimentos nas instituições escolares, acadêmicas e culturais. Como diz Derrida, a escritura envolve:

[...] não apenas os gestos físicos da inscrição literal, pictográfica ou ideográfica, mas também a totalidade do que a possibilita [...] não apenas o sistema de notação que se anexa secundariamente a tais atividades, mas a essência e o conteúdo dessas atividades mesmas [...] (DERRIDA, 1973, p. 11).

Nesse sentido, um dos desafios que se coloca imediatamente diz respeito à existência de um primeiro destinatário dessas leituras/escritas que são os próprios oficineiros, posto que as imagens/mensagens circulam primeiro no circuito fechado das oficinas. Esses primeiros destinatários precisam ser problematizados no seu fazer para liberar o fluxo do endereçamento. Como fazê-lo?

$\mathrm{Na}$ tentativa de responder a esta questão, foram elaboradas exposições e propostas outras dinâmicas de expressão estética, de modo que as composições resultantes dos encontros em oficinas pudessem circular em giros por espaços múltiplos rompendo com o aprisionamento ao lançar aos ventos palavras e imagens postais. A opção por um fazer mais livre, que estimule a criação e a abertura de espaços de aprendizado, privilegiando o diálogo não hierárquico entre os participantes, levou-nos a optar pela oficina. Esta opção pretendeu reti- rar o caráter metodológico escolarizante dessa prática. Lange (2010) aposta em oficinas enquanto espaços de aprenderes e ensinares, que podem escapar do formato escolar, do procedimento pedagógico que este imprime ao contato com a escrita e a leitura, que nem sempre estimula a criação. Concebe encontros que oferecem "[...] ao oficinando um lugar de leitor e de escritor-escrevente independentemente de crivos como certo/errado, bom/ruim [...]" (LANGE, 2010, p. 166). Em consonância com esta abordagem, Preve (2010, p. 135) pontua que "[...] as oficinas são composições e compor é desenhar um lugar [...]". Para estas autoras, as oficinas nunca estão prontas, elas se fazem enquanto acontecem.

A partir das colocações acima, toma-se as oficinas como um dispositivo, considerando que a composição de um lugar de leitor-escrevente e de um espaço de aprenderes e ensinares configura-se a partir do próprio emaranhado de linhas que constitui as oficinas. Ressalta-se aqui o "[...] teor de novidade e criatividade, que marca ao mesmo tempo sua [do dispositivo] capacidade de se transformar [...]" (DELEUZE, 1996, p. 4). A oficina como dispositivo interessa a esta proposta, pois favorece o esgarçamento das identidades constituídas e o estilhaçamento da autoria, enfraquecendo as linhas mais duras em proveito de linhas de subjetivação "[...] capazes de traçar caminhos de criação [...]" (DELEUZE, 1996, p. 4).

A ideia de mixagem de palavras e imagens vem como uma possibilidade de rasurar a autoria e possibilitar a mistura de produções, desvencilhando-as de um lugar identitário para transportá-las a um espaço coletivo, na concepção de um coletivo de criação com palavras e fotografias. Esse processo de aprendizagem inventiva, que se faz através do trabalho com materiais flexíveis, se presta à transfor- 
mação e à criação. Criando e sendo criados, num movimento de coengendramento, faz-se e inventam-se coisas, inventando-se ao mesmo tempo. "Nas oficinas ocorrem relações com as pessoas, com o material e consigo mesmo [...]" (KASTRUP; BARROS, 2009, p. 84).

As oficinas são voltadas para a criação de escritas para caberem em um cartão postal. Essa ideia se ampara em Derrida (2007) para quem as palavras são dadas, são entregues, dispensadas uma a uma, são endereçadas e se voltam a alguém. Espécie de carta aberta, a experimentação em postal ignora a distinção entre frente e verso, aqui ou lá, perto ou longe e, principalmente, a distinção entre o que é mais importante, se "[...] a imagem ou o texto, e no texto, a mensagem ou a legenda, ou o endereço [...]" (DERRIDA, 2007, p. 19).

Essa aproximação vem permitindo a criação de videopoemas, cartões visuais e sonoros em oficinas, na busca por uma política visual, em que palavras/imagens oportunizem a criação de novas visualidades e visagens na relação com a arte. Tais elementos, expressão estética deste projeto, estabelecem conexões profícuas com a proposta de pensar a educação como plano de composição, que desenha o mundo enquanto acontece (AMORIM, 2011, 2012).

Desenhar um lugar: escritas para caber em um cartão postal. Escrita-em-limite do cartão postal aqui pensada com Kiarostami (2004), para quem a moldura de um quadro, o enquadramento de uma cena, (ou um cartão postal?) potencializam a visão da obra e a destacam. Escrever no verso do postal, (com)versando com suas imagens: versos a versar, avesso, reverso.

Criar uma língua que se diz por visibilidades e sonoridades, língua-limite no sentido de Deleuze. Nos dizeres de Sousa Dias, Deleuze pensa
[...] A poesia é de cada vez a criação de uma língua de imagens, de uma língua imagética pura, de uma dizibilidade configuradora de inéditas visibilidades e sonoridades, língua-limite de visões e de audições "não humanas" no sentido de Deleuze. Mas essa língua é sempre em cada caso o único modo rigoroso de "dizer" essas sensações, essas vidências e devires não pessoais, o modo não arbitrário de dizer o indizível. (DELEUZE apud DIAS, 2007, p 284).

O aspecto que interessa é a ideia de fluxo, de pensamento impostado, ao modo de Derrida (2007, p. 19): "Você me dá as palavras, você as entrega, dispensadas uma a uma, as minhas palavras, voltando-as em direção a você e endereçando-as a você $[\ldots]$ ".

A questão da escrita, da leitura e da criação também é abordada por pesquisadores que se utilizam deste aporte conceitual, dentre os quais se destaca o projeto Escrileituras: um modo de ler e escrever em meio à vida ${ }^{5}$. O grupo que o compõe considera que o conhecimento não determina a escrita e a leitura, mas procede delas como experimento do trabalho de alguém que escreve para conhecer, e não de alguém que escreve o que já conhece. Além do aporte conceitual, tem em comum com esta proposta o uso de oficinas como metodologia, oferecidas para a comunidade universitária e para escolas da educação básica, nas quais a experimentação da leitura e escrita é entendida como possibilidade de exercício do pensamento. O grupo que participa da Oficina de Escrita: Psicanálise e Laço Social ${ }^{6}$ propõem-se a pesquisar o ato de escrita tomando a própria escrita como um ato potencial de inscrição da

\footnotetext{
5 Projeto do Programa Observatório da Educação - CAPES/ INEP, coordenado por Sandra Mara Corazza, na UFRGS 6 Esta Oficina é liderada pelo professor Wladimir Antônio da Costa Garcia, da Universidade Federal de Santa Catarina (UFSC), e se insere na Linha de Pesquisa: Ato, Experiência e Construção.
} 
experiência. O trabalho desenvolvido por Mariana De Bastiani Lange examina a noção de endereçamento implicada nos processos de escrita e de aprendizagem que privilegiam "[...] os efeitos do processo de escrita naquele que escreve [...]" (LANGE, 2010, p.168).

Vale destacar ainda as elaborações feitas por Roland Barthes, no final da década de 70 do século passado, a respeito da relação escritor-escrevente. Para o autor seriam estas as duas dimensões da escrita: o escritor como aquele que funciona dentro dos limites da instituição literária, e os escreventes como aqueles que encaram a literatura como meio, e atribuem importância menor à ação de escrever uma obra. De algum modo, todas essas pesquisas em curso, também problematizam a polícia da escrita.

Pretendemos escapar do que Artières (2006) denomina polícia da escrita, que configura o olhar macro da escolarização e aprisiona a possibilidade da criação ao se constituir mais no universo da informação do que naquele da formação. Cabral e Kastrup (2009, p. 288) destacam a importância de operar uma diferenciação entre "[...] uma leitura de aquisição de informação e uma leitura de acolhimento ou à espreita $[\ldots]^{\prime \prime}$. Essa distinção proposta pelas pesquisadoras nos interessa na medida em que se possa ampliá-la, abarcando o universo da escrita. Se para elas outra maneira de ler participa da cognição inventiva, para nós outras maneiras de escrever e ler, implicam necessariamente o risco inerente a essa cognição inventiva.

Oficinar para além da compreensão de que oficinas são dispositivos de produção de subjetividades, nos interessa nesta prática sua dimensão criativa que nos instiga a fazer problema, fazer com outrem, invencionar aprendizagens. Como nos desafia Kastrup (2010, p. $61)$, as oficinas que envolvem práticas artís- ticas consistem "[...] na invenção de si e do próprio mundo [...] são espaços de fazer junto [que] se prestam à transformação e à criação [...]". Com estas funções, o dispositivo oficina opera com materiais flexíveis, permitindo que os participantes estabeleçam "[...] agenciamentos, que são relações de dupla captura (DELEUZE; PARET, 1998), se transformando ao mesmo tempo em que transformam materiais [...]" (KASTRUP, 2010, p. 61). Processo de criação que é ao mesmo tempo autocriação, "[...] a oficina é um espaço de aprendizagem inventiva na medida em que propicia o encontro com a virtualidade de si, produzindo a experiência concreta de invenção de si e do mundo [...]" (KASTRUP, 2010, p. 62).

A cada oficina, novos encontros trouxeram possibilidades de/para (re-in)ventar, e exercícios de cognição inventiva nos colocaram à espreita, nos aguçaram sentidos numa antropofágica degustação-banquete-oferenda de imagens e palavras. Neles, a aproximação inicial (devoração) convidava a escolhas - de objetos, imagens, textos - que geravam composições com-partilhadas na/pela palavra, cujo foco é a experimentação pela poesia falada, spokenword ${ }^{7}$. Esta é uma forma de arte literária ou uma performance artística em que as letras de músicas, os poemas ou as histórias são faladas ao invés de cantadas. No spokenword a ênfase recai na pessoa que fala e se encontra no limite entre gêneros artísticos. O que nos interessou foi fazer notar possíveis encadeamentos e ressonâncias entre diferentes poemas, a partir dos quais se configuraria um coletivo escrevente. Esta prática mostrou-se potente

\footnotetext{
7 Aos moldes do que se vê no documentário Cartas pra Angola (2010), dirigido por Coraci Ruiz e Julio Matos, no qual um grupo de pessoas pratica o spokenword como forma de resistência política-poética. O filme aborda a relação entre brasileiros e angolanos que vivem entre Brasil, Angola e Portugal, por meio da troca de vídeo cartas. Disponível em: <www.laboratóriocisco.org> Acesso em: 17 maio 2012.
} 
para nossa aposta por uma criação menos centrada no que se pensa ou se expressa, e mais pelo que se cria na abertura de encontro entre mundos e processos de autocriação. O procedimento utilizado na montagem de imagens e textos para a composição dos postais privilegiou o gesto apropriativo, em que a mixagem envolveu práticas as mais diversas: a colagem, a laceração (rasura), a compressão e a acumulação ${ }^{8}$, garantindo que o resultado dessa produção não estivesse previamente determinado.

Pela criação, interrogamos modos de existir em um incessante desaprender que propicia a experimentação, escapando da lógica de acumulação e medição de conhecimentos. O que nos interessa é esta dimensão de experiência e abertura, os efeitos que produzem sobre a subjetividade e com isso se inscreve e amplia a experiência educacional. Nesse sentido, se para Barthes (1977) o escrevente alarga o seu círculo de relações a toda a sociedade e inscreve-se na História, para nós, ao contrário, interessa a escrita e a leitura que desfaz círculos pré-existentes e escapa à História.

\section{As Criações ${ }^{9}$}

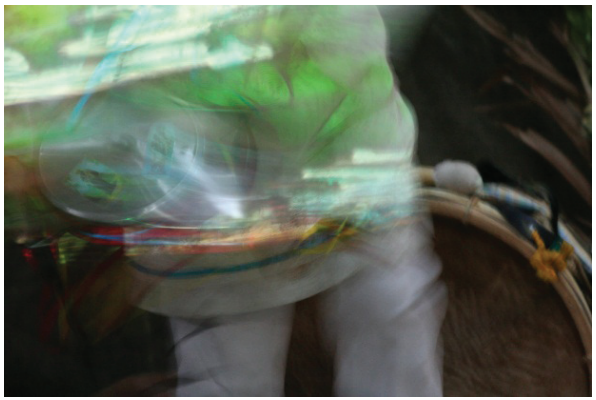

\footnotetext{
${ }^{8}$ Essas práticas foram utilizadas como técnicas por diferentes artistas ao longo do século XX.

9 Seleção de imagens e poemas criados em diversas oficinas de criações do projeto por estudantes universitários e de ensino médio, pesquisadores e artistas convidados. Considera-se coletiva a autoria dos textos e imagens.
}

lancei-me de muitas lentes para prender o vento na película fina de cartões-postais as fotos ficaram paradas e vento vazou por entre as bordas delas

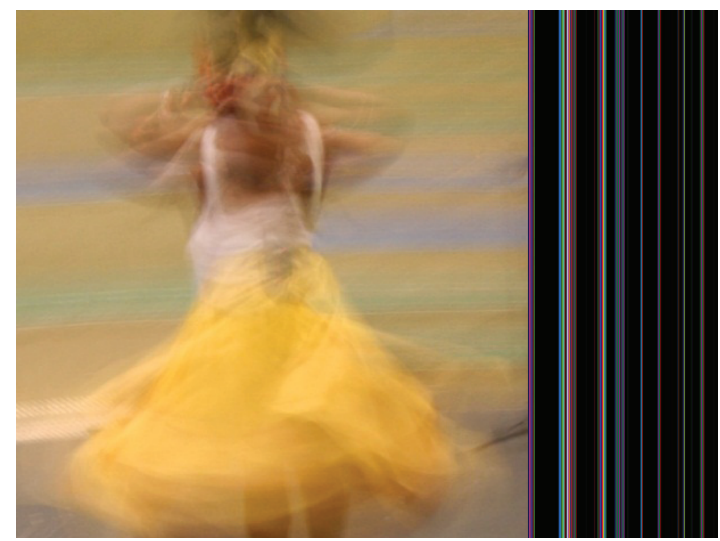

lancei-me de corpo inteiro boca, olho, ouvido, verbo, imagem, som abri a boca para engolir o vento mas o vento escapou pelos meus cabelos

abri o cabelo para engolir o vento mas o vento escapou pela minha boca e o vento chamou mais vento e o vento veio para balançar

perfure

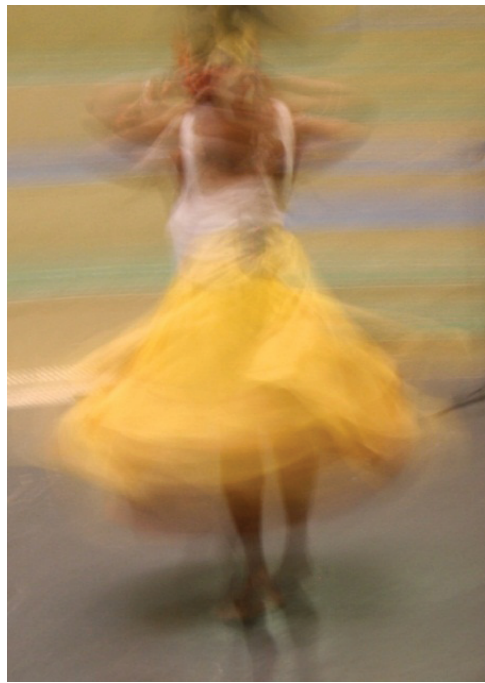

misture ventre vente vento (in) vente leve 
o que segura

o que fica

palavra armadura imagem sem rasura

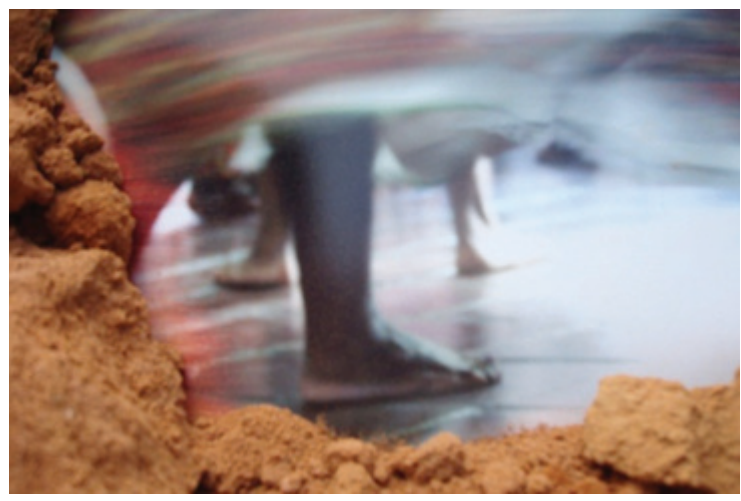

por áfricas-cartões-postais destinatários indeterminados inusitados passeiam pela superfície em imagens visagens vertigens desordens lugares...

ecoAR na palavra

a cor

o AR na palavra

é cor eco AR na palavra e coAR da palavra

a cor

e A coR na palavra

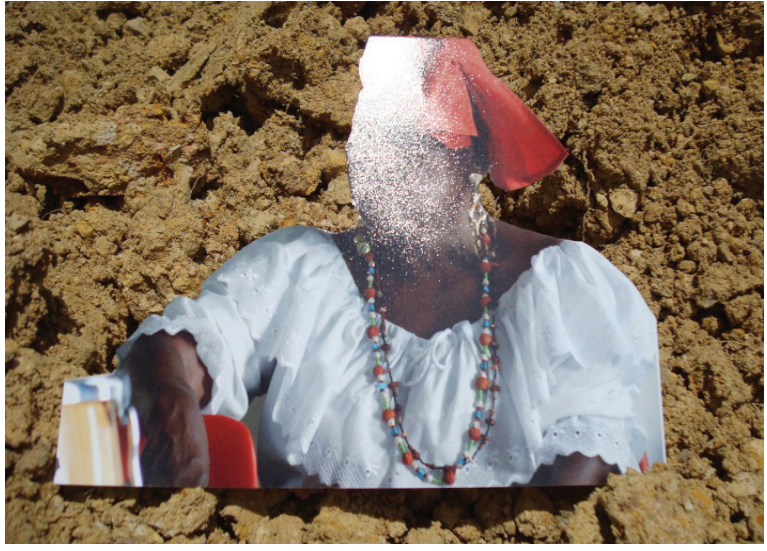

a terra

a lama

memória apagada a chuva levou embora

do lugar onde nasci, saí escolhi o caminho exigente à terra não devo nada a não ser a memória das pedras

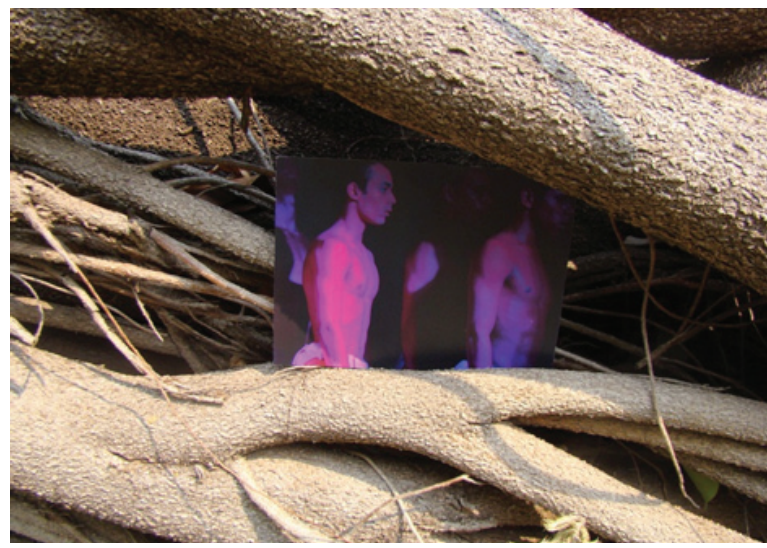

luandas

luares...

lares?

mares.

ires 


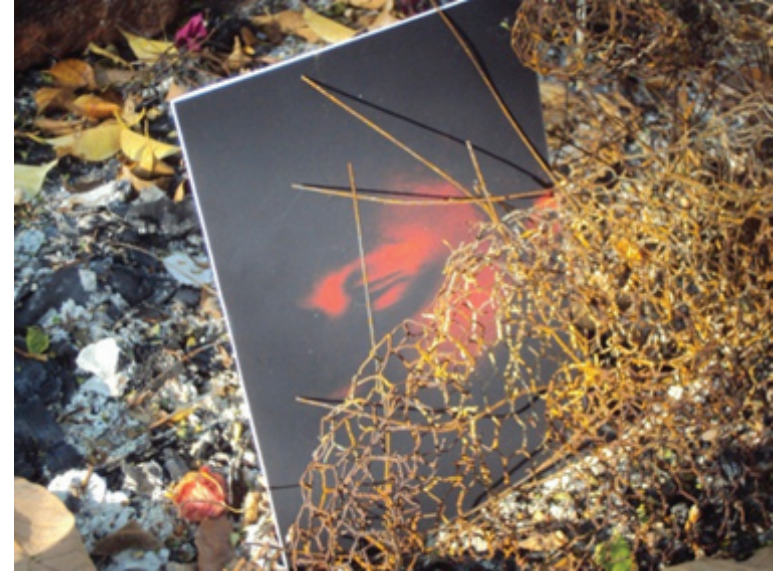

vires...

vibrar no eco do grito que já não se ouve na tensão deste silêncio oco oco oco

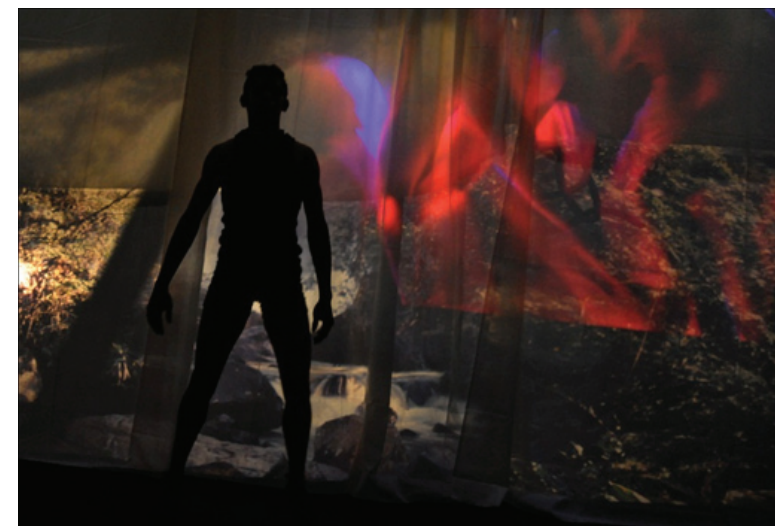

imagem-palavra

machuca

desenha, risca, rói

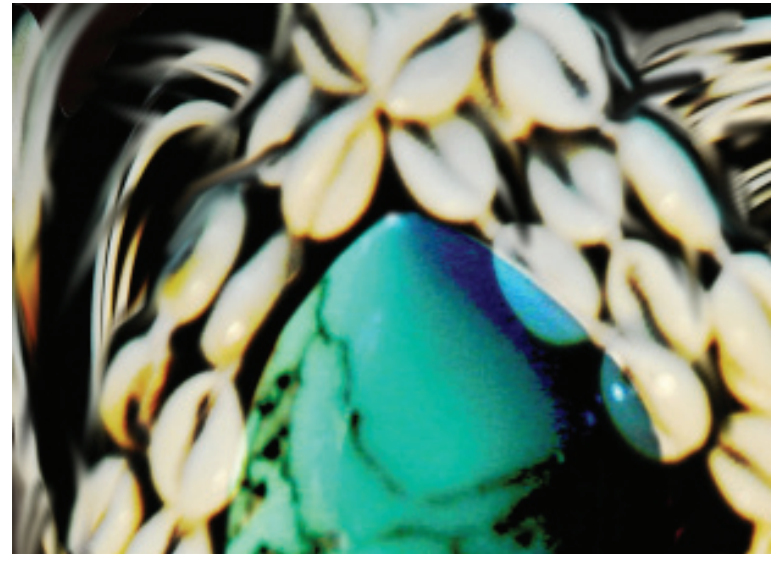

bloco de pedra amarrada quando cai n'água

suor

lágrimas

risos

cores

há um esverdear

com lembranças perdidas do que quis ser

azul

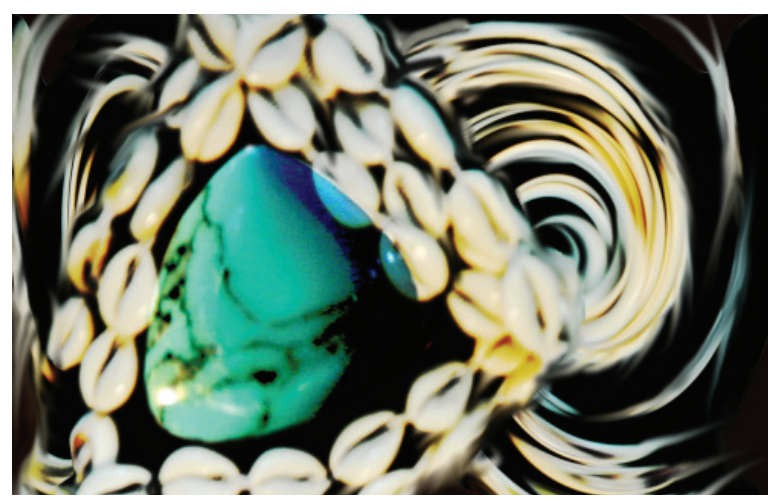

compor um desenho sonoro

soar diferentes matizes

de forças

venta o (i)material

sons em cores, cores de sons

cintilam imagens 


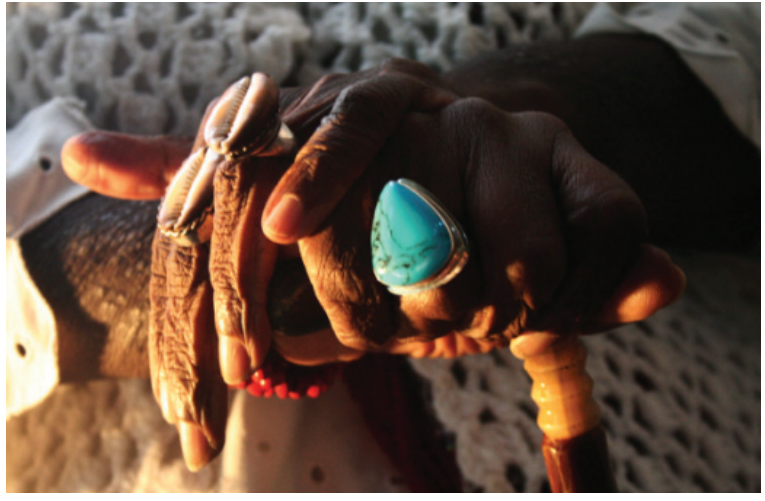

mãos em alegre poetagem

enviam frutos

recombinados em cores pura mixagem que se mestiça em peles o grito

a dor

\section{e a alegria}

\section{o tambor}

e os silêncios

sonoros

da arte

palavras-águas-vivas

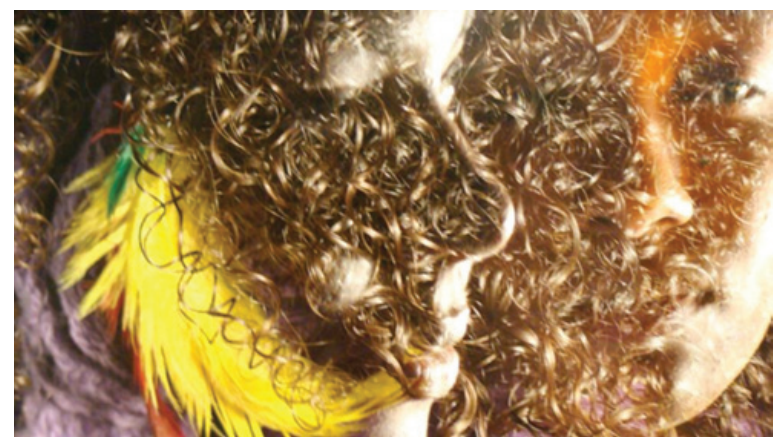

Linhas tênues entre aqui e lá entre eles e nós um emaranhado que move que é fronteira fluida de mares profundos

sol

luz

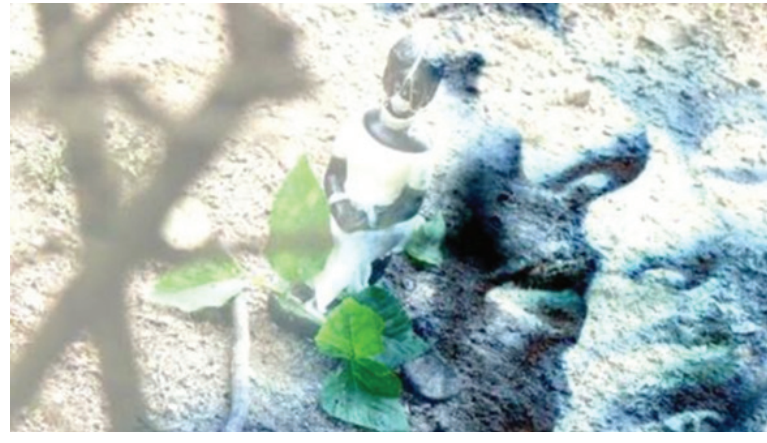

sombra

escuridão

infinitos desejos e emoções

que se encontram

em olhares

das áfricas

de vivas cores e tons

ventam

escrever encontros

ins-pirar

textos e postais e poetagens

\section{Criar, Fragmentar, Endereçar e Coletivizar Cartões-Postais... Edu- car?}

Entler (2011) escreve sobre o redimensionamento da autoria fotográfica pelos movimentos contemporâneos, que propõem ações coletivas no campo das artes. Os coletivos problematizam e colocam em suspensão a necessidade autoral-pessoal das criações, assumindo que a arte se faz num processo de criação colaborativa. Neste processo, o que se destaca nas obras é o nome do coletivo, e não dos artistas que o compõem. A partir desta ideia, pode-se pensar que "[...] qualquer linguagem pertence à cultura, não ao indivíduo: o autor se 
constitui sempre a partir de uma apropriação de um bem coletivo [...]" (ENTLER, 2011, p. 2). Desta forma, até a mais simples captação de imagem estará "[...] atravessada por um gesto maior do que o do próprio artista $[\ldots]$ " (ENTLER, 2011, p. 1).

Também nos interessou desequilibrar o caráter autoral das fotografias, bem como das produções escritas, para que se deixem atravessar por composições, misturas, mixagens numa criação colaborativa entre diferentes pessoas. As criações realizadas no projeto são de autoria do Coletivo Fabulografias. As oficinas que ocorrem em escolas, na universidade, nos espaços culturais vão expandindo este coletivo, formado por todos aqueles que um dia debruçaram-se criativamente sobre imagens e palavras a partir da pergunta mobilizadora. As pessoas mudam, ficam os postais, que são inspiração inicial para os novos encontros. Os percursos foram evidenciando que o apagamento/ estilhaçamento da autoria não operava pela afirmação identitária, mas pela proliferação de linhas de subjetivação. Assumindo a possibilidade de criação coletiva movida pelo encontro e pelo contágio do outro - pessoa, objeto, palavra, gesto, som, imagem... - operou-se na/ pela diferença, permitindo os agenciamentos e invenções de outros modos de estar/existir, menos pela condição de posse e mais pela de partilha.

Educar: assumimos a pulsão verbal desta palavra despindo-a de sua função autoritária, emissora de palavras de ordem, e nos inspirando numa educ/ação dos/pelos encontros, da/na potência das composições coletivas, inscrevendo-a num campo político-poético estético de pensamento. Ícones transformavam-se a cada oficina; objetos trazidos e fotografados desdobravam-se em composições; os sentidos estavam em constante deslocamento, as expe- rimentações operavam pela via do contágio em interações impensadas no caos da criação. As oficinas de experimentação com imagens e palavras se configuraram como um procedimento capaz de nos fazer pensar a educação como plano de composição, deslocando-a da dimensão de controle e domesticação, para aquela que problematiza criativamente a multiplicidade. Experiências que podem se configurar enquanto práticas pedagógicas que afirmam as diferenças, os devires, potencializando os encontros e fomentando o desejo pelo distante. Interessam-nos os "[...] deslizes, os movimentos dispersivos e superficiais que privilegiam singularidades não individuais, que resistem ao jogo da comunicação-recognição que as máquinas imagens-pensamentos impõem [...]" (AMORIM, 2012, p. 48). Não interessa nomear, explicar, contextualizar ou gerar uma consciência sobre, mas gerar um movimento de encontros entre intensidades e sensações em que a força reside e se dispersa por entre as palavras e imagens dos cartões-postais.

Sentir, pensar e criar ventos-áfricas com imagens e palavras num coletivo que é possível na conexão gerada pela composição entre poemas e imagens e no convite que fazemos à entrada neste fluxo de criações. Quando a potência recai às imagens e às palavras retira-se a centralidade no sujeito-autor, tão caro à modernidade: "[...] sujeito que produz um discurso em que se reconhece de forma coerente, um discurso pelo qual deve se responsabilizar e que, em contrapartida, pode reivindicar como sua propriedade [...]" (ENTLER, 2011, p. 5). Nas criações não se exigem explicações e coerências. A linguagem é um jogo, um gesto de entrega às ficções coletivas. Os postais chegam como um vento que passa, pedem gestos apropriativos, mixagens, recortes, colagens, rasuras, fragmentações, des-continuidades. 
Da composição criativa do pensamento e da arte, derivam a mixagem entre palavras e imagens e conversas educação/imagem/ cultura em tempos de novas tecnologias. Os postais convidam para um gesto de criação movido pela potência efêmera das palavras e das imagens da contemporaneidade, afirmam o endereçamento em aberto que as redes sociais e mídias digitais criam. Interessa pensar em como as artes - literatura, fotografia em especial - movimentam-se resistindo e afirmando estas potências. Há aí algo à perseguir, efeitos intensivos que provém das imagens e palavras na contemporaneidade: a perda da potência autoral, a fragmentação, a efemeridade, a ficção e o endereçamento em aberto. Novos tempos-ventos a perseguir e a resistir...

\section{Referências}

AMORIM, A.C.R. Currículo, Tempo Perdido. In: FERRAÇO, C.E. Cotidiano Escolar, Formação de Professores/as e Currículo. São Paulo: Cortez, 2011. p. 112-127.

AMORIM, A.C.R. de. Deleuze e Currículo no Intervalo de Palavras e Imagens. In: FERRAÇO, C.E.; GABRIEL, C.T.; AMORIM, A.C.R. (Org.). Teóricos e o Campo do Currículo. Campinas, SP: FE/UNICAMP, 2012. (E-book GT Currículo) p. 43-55.

ARTIÈRES, P. A Polícia da Escritura: práticas do panóptico gráfico. In: KOHAN, W.O.; GONDA, J. Foucault 80 Anos. Belo Horizonte: Autêntica, 2006. p. 37-49.

BARTHES, R. Escritores e Escreventes. In: BARTHES, R. Ensaios Críticos. Lisboa, Ed. 70, 1977. p. 205-215.

BARTHES, R. O Grau Zero da Escrita. Lisboa, 1989.

CABRAL, M.C.C.; KASTRUP, V. Leitura de Acolhimento: uma experiência de devir consciente. Psicologia: reflexão e crítica, Porto Alegre, v. 22, n. 2, p. 286-293, 2009.

DELEUZE, G. O Mistério de Ariana. Lisboa: Ed. Vega, 1996.

DELEUZE, G. A Imagem-tempo: cinema 2. Tradução: Eloisa de Araujo Ribeiro. São Paulo: Brasiliense, 2007.

DELEUZE, G.; PARNET, C. Diálogos. Tradução: Eloisa Araújo Ribeiro. São Paulo: Escuta, 1998.

DERRIDA, J. Gramatologia. São Paulo: Perspectiva, 1973. 
DERRIDA, J. Cartão-Postal: de Sócrates a Freud e além. Tradução: Simone Perelson e Ana Valéria Lessa. Rio de Janeiro: Civilização Brasileira, 2007.

ENTLER, R. Os Coletivos e o Redimensionamento da Autoria Fotográfica. Revista Studium, Campinas, SP, n. 32, [2011?]. Disponível em: <http://www.studium.iar.unicamp.br/32/3.html> Acesso em: 11 mar 2014.

KASTRUP V. Atualizando Virtualidades: construindo a articulação entre arte e deficiência visual. In: MORAES, M.; KASTRUP, V. (Org.). Exercícios de Ver e Não Ver: arte e pesquisa com pessoas com deficiência visual. Rio de Janeiro: Nau, 2010. P. 52-73.

KASTRUP, V.; BARROS, R.B. de. Movimentos-Funções do Dispositivo na Prática da Cartografia. In: PASSOS, E.; KASTRUP, V.; ESCÓSSIA, L. da (Org.). Pistas do Método da Cartografia: pesquisa-intervenção e produção de subjetividade. Porto Alegre: Sulina, 2009. P. 76-91.

KIAROSTAMI, A. Abbas Kiarostami. São Paulo: Cosac Naify, 2004.

KRAUSS, R. O Fotográfico. Tradução: Anne Marie Davée. Barcelona: Ed. Gustavo Gilli, 2002.

LANGE, M.B. Caminhares: fragmentos sobre oficinas de escrita e interrogações sobre os ensinares e os aprenderes. Revista Conjectura, Caxias do Sul, v. 15, n. 3, p. 165-174, set./dez. 2010.

DIAS, Sousa. Partir, Evadir-se, Traçar uma Linha: Deleuze e a literatura. Educação, Porto Alegre, v. 30, n. 2, p. 277-285, maio/ago. 2007.

PREVE, A. M. H. Mapas, prisão e fugas: cartografias intensivas em educação. Tese de doutorado. Universidade Estadual de Campinas, FE. Campinas: SP, 2010.

WUNDER, A.; DIAS, S.O. Deslizes Pelas Superfícies do Acontecimento Fotográfico. Revista Estudos Universitários, Sorocaba, SP, v. 36, n. 1, p. 157-174, jun. 2010.

Submetido para avaliação em 05 de abril de 2013. Aprovado para publicação em 17 de agosto de 2014.

Alik Wunder: Universidade Estadual de Campinas - Campinas - SP - Brasil. Email: alik.wunder@gmail.com Alda Regina Tognini Romaguera: Universidade de Sorocaba - Sorocaba - SP - Brasil. Email: aldaromaguera@ hotmail.com 